\title{
COPARTICIPAÇÃO DE ALUNOS E ALUNAS NA PESQUISA: COMPARTILHAR E CRIAR SIGNIFICADOS SOBRE A ESCOLA ${ }^{1}$
}

MATTOS, Carmen Lúcia Guimarães de ${ }^{2}$

ALVES, Walcéa Barreto ${ }^{3}$

\section{RESUMO}

Este artigo tem como objetivo iniciar uma discussão teórico-metodológica sobre a coparticipação de alunos, alunas em pesquisas educacionais. Apresenta alguns dos resultados da pesquisa etnográfica "Gênero e Pobreza: Práticas, Políticas e Teorias e Tecnologias Educacionais - Imagens de escolas" (MATTOS, 2013). As bases que orientaram a pesquisa foram: os fundamentos da etnografia expressos nos estudos sobre colaboração e reflexividade (ERIKSON, 2006; MATTOS; CASTRO, 2011; ALVES, 2003, 2012; MOURÃO, 2006, 2011); as diferentes formas de coparticipação de alunos como agentes do conhecimento escolar pautadas nos estudos sobre "a voz do aluno" [Student Voice] (COOK-SATHER, 2002; GRION; COOK-SATHER, 2013); e, os princípios da pesquisa-crítico-participativa a partir de uma concepção mais democrática e simétrica de poder entre os membros da equipe (FINE, 2013). A pesquisa foi desenvolvida em colaboração entre dois grupos: um do Colégio Estadual Comendador Soares (CECS) e o outro do Núcleo de Etnografia em Educação da UERJ. Os principais resultados da pesquisa confirmam que foi uma experiência positiva para os grupos envolvidos e que pode modificar as formas de desenvolver pesquisas nas escolas.

Palavras-Chave: Coparticipação - Voz do aluno - Etnografia - Pesquisa-Crítico-Participativa - Reflexividade.

\section{ABSTRACT}

This article aims to initiate a theoretical-methodological discussion about students' coparticipation in educational research. It presents some of the results of the ethnographic research "Gender and Poverty: Practices, Policies, Theories and Educational Technologies -

\footnotetext{
${ }^{1}$ Este artigo é parte dos resultados da pesquisa "Gênero e Pobreza: Práticas, Políticas e Teorias e Tecnologias Educacionais - Imagens de escolas (MATTOS, 2013) que contou como os seguintes financiamentos: Programa Prociência UERJ; Programa de Apoio à Melhoria da Escola Pública do Estado do Rio de Janeiro da Fundação Carlos Chagas Filho de Apoio à Pesquisa do Estado do Rio de Janeiro (FAPERJ); Programa de bolsas da Fundação CAPES do Ministério da Educação (MEC), do Conselho Nacional de Pesquisa Científicas (CNPq) e da Sub-reitoria de Pesquisa (SR2/UERJ); e do Programa Professor Visitante do Exterior SR2/UERJ e Special Studies Program (SSP) [Programa Especial de Estudos] da University of Sydney, Austrália.

${ }^{2}$ Professora da Faculdade de Educação da Universidade do Estado do Rio de Janeiro.Email: clgmattos@gmail.com

${ }^{3}$ Professora da Faculdade de Educação da Universidade Federal Fluminense. Email: walcea@yahoo.com.br
} 
Images of Schools" (MATTOS, 2013). The bases that guided the research were: the foundations of ethnography expressed in the studies on collaboration and reflexivity (ERIKSON, 2006, MATTOS, CASTRO, 2011, ALVES, 2003, 2012, MOURÃO, 2006, 2011); the different forms of student participation as agents of school knowledge based on the Student Voice (COOK-SATHER, 2002; GRION, COOK-SATHER, 2013); and, the principles of researchcritical-participatory from a more democratic and symmetrical conception of power among team members (FINE, 2013). The research was developed in collaboration between two groups: one from the Comendador Soares State School and another from the Nucleus of Ethnography in Education of UERJ. The main research results confirmed that it was a positive experience for the groups involved and that can it can modify ways of conducting research in schools.

KeYwORDS: Co-participation, Student Voice, Ethnography, Critical-Participatory-Research, Reflexitivity.

\section{INTRODUÇÃO}

Apesar da história pedagógica do Brasil ser caracterizada pela presença de educadores renomados como Paulo Freire, Anísio Teixeira e Florestam Fernandes, que acentuaram a importância de se ouvir e incluir a voz do aluno como um importante elemento na construção do conhecimento escolar, escolas brasileiras até hoje parecem pouco sensíveis à importância de dar aos alunos um papel mais central nos processos escolares. No protagonismo pedagógico, ainda prevalece as vozes dos professores e gestores escolares.

Infelizmente, em todo o país, muitos jovens ainda são vistos simplesmente como "números": eles que devem ir à escola para ouvir com atenção as lições, fazer atividades da melhor maneira possível, fazer um esforço maior para estudar e mostrar os melhores resultados em termos de desempenho. $O$ que esses jovens pensam sobre a escola e seu ambiente circundante, como podem contribuir de forma ativa e intencional para os processos que se desenvolvem ali, que papel podem ter na sua vida escolar - que é um lugar que, durante muitos anos, eles continuarão a sua vida quotidiana - são aspectos que parecem pouco importar para os sis- temas educacionais, escolas, professores, gestores e pesquisadores educacionais.

A ausência da voz do aluno em pesquisas educacionais é desafiada na experiência descrita neste texto. A relevância dessa prática em pesquisa é explorada em detalhes revelando o que o aluno tem a dizer sobre as práticas e conhecimentos escolares presentes em salas de aula. As práticas reveladas são informações privilegiadas que pesquisadores e professores têm acesso para compartilhar alternativas inovadoras de como se conduzir pesquisas, políticas e práticas nas escolas.

As pesquisas que utilizam essa abordagem são encorajadoras e afastam o fantasma da invisibilidade de alunos e alunas do panorama opaco existente nas pesquisas sobre o mundo da escola. Elas reconhecem os estudantes como coparticipes de pesquisa e enfatizam a necessidade de escutá-los para entender melhor os contextos educacionais em que eles vivem.

Nas escolas, as práticas pedagógicas e as pesquisas que utilizam a perspectiva da "voz do aluno" [Student Voice] (GRION; COOK-SATHER, 2013) são promissoras no Brasil e no mundo. Embora 
algumas dessas pesquisas não explorem, especificamente, os princípios da abordagem "student voice" originários dos seminários do grupo de pesquisadores da Universidade de Cambridge, Inglaterra que recontextualizaram esse enfoque (COOKSATHER, 2011), esta abordagem está presente, mesmo que de forma tímida, nas práticas pedagógicas e pesquisas acadêmicas no Brasil.

Portanto, esse texto oferece um pequeno retrato das práticas do grupo de pesquisa - Etnografia e Exclusão em Educação, registrado nos Grupos de Pesquisa no Brasil (GRPSq) do Conselho Nacional de Desenvolvimento Científico e Tecnológico (CNPq)desde de $2004^{4}$, e que se inclui nas atividades do Núcleo de Etnografia em Educação (NetEDU) descrevendo os resultados da pesquisa intitulada: Gênero $e$ Pobreza: práticas, políticas e teorias educativas - imagens da escola" (MATTOS, 2013). A pesquisa foi desenvolvida em uma escola pública de Ensino Fundamental e Médio do Estado do Rio de Janeiro no período de agosto de 2010 a julho de 2013.

Ao longo do texto, vinhetas ilustrativas e recomendações revelam alguns princípios que guiaram o estudo, entre eles, o que adverte que o estudante precisa desenvolver o ethos da responsabilidade em contextos onde ele possa escolher e agir com consciência crítica e reflexividade. E assim, se comprometer pessoalmente com o desenvolvimento de ideias e ações voltadas para a melhoria contínua da sua própria vida, da escola e da comunidade.

A ideia que emerge da coparticipação de alunos e alunas na pesquisa é a da responsabilidade de todos como atores e co-

\footnotetext{
${ }^{4}$ Acesso ao Diretório dos Grupos de Pesquisa no Brasil do Conselho Nacional de Desenvolvimento Científico e Tecnológico (CNPq) em <http://lattes.cnpq.br/web/dgp/home>
}

autores da vida escolar; responsabilidade em pensar o sistema educativo como parte da formação de cidadãos capazes de participar conscientemente na criação e cocriação de coletividades mais amplas e diversas e, portanto, incluir essas diversidades considerando os pontos de vista de todos na construção do conhecimento.

\section{BASES METODOLÓGICAS}

EPISTEMOLÓGICO-

As bases que orientaram a pesquisa explorada nesse texto foram: os fundamentos da etnografia expressos nos estudos sobre colaboração e reflexividade (ERIKSON, 2006; MATTOS; CASTRO, 2011; ALVES, 2003, 2012; MOURÃO, 2006, 2011); as diferentes formas de coparticipação de alunos como agentes do conhecimento escolar pautadas nos estudos sobre "a voz do aluno" [Student Voice] (COOK-SATHER, 2002; GRION; COOKSATHER, 2013); e,os princípios da pesquisa-crítico-participativa a partir de uma concepção mais democrática e simétrica de poder entre os membros da equipe (FINE, 2013).

Embora nas pesquisas desenvolvidas pelo NetEDU os fundamentos da etnografia que se apoiam nas práticas de colaboração e reflexividade já tenham sido amplamente descritos (MATTOS; FONTOURA, 2009; MATTOS; CASTRO, 2011; MATTOS at. al., 2015), neste texto, retomaremos alguns dos elementos básicos sobre os quais se estruturam essas práticas na pesquisa etnográfica.

Mattos (1992) criou o modelo "bottom-up" de pesquisa cujo princípio de coleta de dados emana da base (o aluno) para o topo (gestores educacionais). Nele, por um processo nomeado por "corrente dialógica", a voz do primeiro informante (o aluno) é ouvida pelo segundo (o professor) e subsequentemente pelos outros sujeitos que fazem parte da cadeia hierárquica de poder na cultura política da esco- 


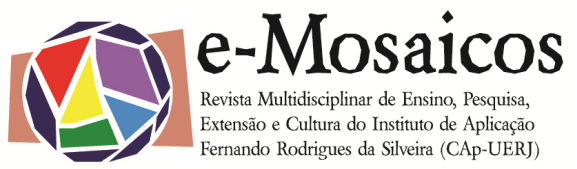

la. Essas falas são "inversamente" associadas, sendo a voz do "menos empoderado" ouvida pelos "mais empoderados". A partir deste modelo, Mattos considera a viabilidade de uma aplicabilidade significativa dessa prática, nas ações educacionais e na pesquisa. O ponto relevante deste modelo é a construção conjunta das vozes da escola onde a voz do aluno é preponderante. As compreensões que o aluno tem sobre a escola, seu papel social e educativo é construído por uma "memória coletiva" (CASTRO, 2006).

Erickson (1989, 2006) e Mattos (1995) descrevem os principais elementos da prática colaborativa em etnografia. Embora nesses artigos os autores explorem a colaboração entre professores e pesquisadores, nesta pesquisa a colaboração se deu entre os alunos e alunas (os pesquisados)e os pesquisadores. Ambos os autores argumentam que, na dinâmica interativa da colaboração, a confiança e o risco são componentes essenciais dessa interação. Assim, compartilhar igualmente às escolhas sobre as ações da pesquisa fortaleceu os laços de confiabilidade entre pesquisadores e pesquisados.

Da mesma forma, a reflexividade na pesquisa etnográfica em educação, tem sido explicada na esfera das percepções dos pesquisadores, professores e gestores. $\mathrm{O}$ aluno mais uma vez fica invisível. O sentido da reflexividade nestes sujeitos, na maioria das vezes, é a mesma defendida por Bourdieu (2005) quando explora a noção de "objetivação participante" (p.52). Entretanto, as pesquisas do NetEDU (ALVES, 2003; 2012 MOURÃO, 2006; 2011), utilizam autores como: Back (1997), Lash (1997), Giddens (1990), Goffman (1985), para recriam a noção de reflexividade entre os alunos e alunas participantes de suas pesquisas.

De acordo com Alves (2003), a "reflexividade" está intimamente ligada à imagem que o outro reflete sobre o indiví- duo, o que provocaria neste um retorno a si mesmo" (p.2). Ela explica:

\begin{abstract}
Entendemos que a reflexividade é um processo que se inicia pelo espelhamento, onde o sujeito se vê através da sua interação com o outro e das vivencias que ocorrem em seu convívio social, refletindo-se sobre, com e através do outro. [...] tem um caráter auto avaliativo: o individuo se vê através da imagem que foi espelhada pelo outro e usa a reflexão para avaliar suas próprias concepções, seu comportamento, culminando, por vezes, numa mudança de postura diante do auto confrontação do sujeito a partir do reflexo de si pelo outro (ALVES, 2003, p.39).
\end{abstract}

Enquanto Mourão (2011), em conformidade com Alves (2003; 2012) analisa as falas dos alunos participantes demonstrando o potencial da reflexividade entre eles, ela narra,

[...] quando convidados ao diálogo por meio dos grupos focais, [alunos e alunas] apresentaram algumas ambivalências e contradições em relação ao que pensam. Essas ambivalências e contradições pareceram bastante positivas, pois, possivelmente, surgiram como resultado de algumas reflexividades que emergiram das discussões com os colegas e com a equipe de pesquisa. A possibilidade de trocarem opiniões sobre seus diversos pontos de vista, que eram confrontados ou aceitos entre eles, permitiu-lhes refletir, mudando-os ou mantendo-os. A prática dessa dialética, que muitas vezes era carregada de componentes emocionais, os levou a certa reflexividade sobre as opiniões que inicialmente emitiam com pouca visão crítica da realidade, bem como a perceber, algumas vezes, questões ocultas em meio as abordadas 
e-Mosaicos - Revista Multidisciplinar de Ensino, Pesquisa, Extensão e Cultura do Instituto de Aplicação Fernando Rodrigues da Silveira (CAp-UERJ)

que, quando desvendadas por eles em alguns momentos,conduzia-os a uma dura reflexão crítica sobre suas condições de vida" (p.87).

A coparticipação de alunos e alunas como agentes do conhecimento escolar é um enquadre teórico-metodológico que se apóia nos estudos de Cook-Sather (2002). Ela explica que a "voz do aluno é orientadora dos resultados da pesquisa" (p. 5) e que essa voz, precisa prevalecer tanto nos objetivos políticos, como os pedagógicos nas práticas de pesquisa e de ensino. A pesquisadora alerta que para isso acontecer essas práticas e pesquisas devem: desafiar o modelo tradicional de ensino segundo o qual teóricos e pesquisadores geram conhecimentos e os passam para os professores; alterar a dinâmica de poder na relação professor-aluno; preparar professores comprometidos a agirem sobre as perspectivas dos alunos; e, promover a consciência crítica no aluno sobre as suas experiências e oportunidades educacionais, de modo que este adquira mais confiança em expressar o que precisa como aprendiz (COOK-SATHER, 2002, apud, MATTOS; ALVES, 2015, p.5). Os desafios propostos por esse modelo foram elencados a seguir (Figura 1).

Figura 1: Desafios - "Student Voice".

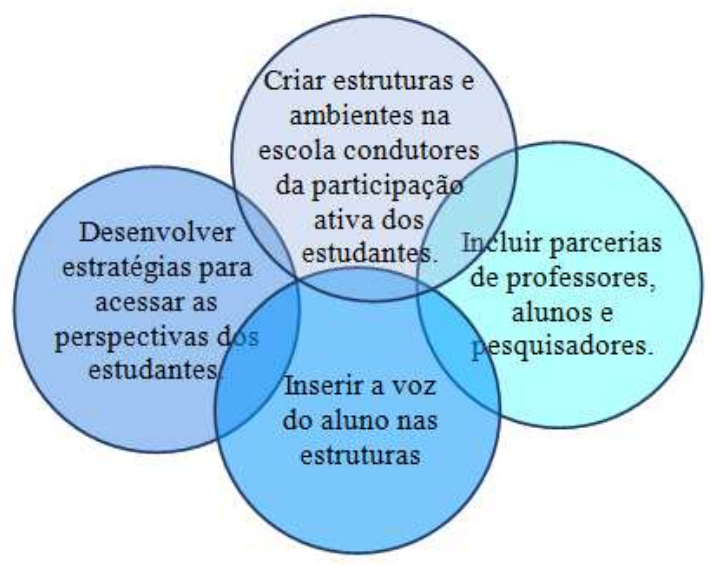

Fonte: COOK-SATHER (2011), p.10 (tradução nossa).
A Figura 1 exibe interseções entre diferentes ações a serem desenvolvidas quando se aplica o modelo do "student voice", que inclui o desafio da substituição de práticas tradicionais de exclusão de alunos e alunas da pesquisa e do ensino, por práticas coparticipativas em todos os níveis de conhecimento que perpassam a estruturada escola.

Um outro modelo de trabalho envolvendo alunos e alunas na pesquisa decorre dos estudos de Michelle Finena City University of New York (CUNY). Eles se pautam nos princípios da "pesquisa-críticaparticipativa". Em entrevista, Fine (2013) explica como utiliza esses princípios em suas pesquisas, ela diz,

[...] a pesquisa é realizada em aliança entre universidades, pesquisadores, estudantes de graduação, ativistas, jovens em desvantagem social e membros de diversas comunidades e instituições da cidade, procuradores públicos, advogados, entre outros. [...]. Existe uma prioridade em ouvir, de forma igualitária, as vozes de todos os participantes, em especial os marginalizados socialmente. [...] pessoas de diversos segmentos sócio educacionais se reúnem com os pesquisadores e, juntos, partilham conhecimentos e criam as questões da pesquisa, os instrumentos, as amostras, as análises e os produtos [...] todos os membros da equipe são treinados juntos sobre métodos de pesquisas, projetos e epistemologia. Todas as diferentes vozes são consideradas e as diferentes opiniões são colocadas no campo de compreensão e negociação. [...] a chave para que isso aconteça é acreditar na "ação de pesquisa crítica participativa", de forma que as pessoas que viveram injustiças e que tem um entendimento íntimo sobre os caminhos pelos quais a injustiça opera, possam ter liberdade para relatar esses 
eventos (FINE, 2013, apud MATTOS; ALVES, 2015, p. 3-4).

As pesquisas do NetEDU nem sempre atendem plenamente os princípios descritos por Fine, mas em vários projetos desenvolvidos contou-se com a participação de juízes, advogados, psicólogos, assistentes sociais, dentre outros profissionais e membros da comunidade "não acadêmica",como colaboradores e pesquisadores junto a equipe principal (MATTOS, 2000). Na pesquisa que se descreve, esse envolvimento foi de coparticipação de alunos e alunas do Ensino Fundamental e Médio como pesquisadores em todo o processo da pesquisa.

Portanto, a contribuição das abordagens e princípios mencionados acima, não se restringiram a eles próprios, na medida em que as práticas de pesquisas que orientam a pesquisa foram,preponderantemente etnográficas. Entretanto houve uma mesclar de estratégias cujo objetivo foi evidenciar o potencial do aluno como agente de transformação da escola.

\section{A PESQUISA-COMPARTILHAR E CRIAR SIGNIFICADOS SOBRE A ESCOLA}

A partir desses pressupostos teóricos-epistemológicos-metodológicos apresentar-se-á os passos seguidos para o desenvolvimento da pesquisa. Eles foram moldados nos princípios da colaboração e coparticipação, ou seja, houve adesão espontânea dos participantes ao estudo assim como o compromisso de toda a equipe em respeitar as negociações feitas entre os seus membros. Assim, foi construída uma rede, negociando significados e explorando de forma curiosa e genuína; a coleta, as análises e a escrita de resultados. Logo, foi desenvolvida uma parceria com base na igualdade de condições entre os dois grupos que formaram a equipe da pesquisa: o primeiro, será nomeado "grupo da UERJ", formado por integrantes do Núcleo de Etnografia em Educação (NetEDU $)^{5}$ da Universidade Estadual do Rio de Janeiro (UERJ) e o segundo, "grupo do CECS", formados pelo pessoal do Colégio Estadual Comendador Soares (CECS) ${ }^{6}$.

A equipe de pesquisa integrou 16 (dezesseis) pessoas do grupo da UERJ e 41 (quarenta e uma) do grupo do CECS. $O$ grupo da UERJ foi formado por: uma coordenadora, dois professores visitantes estrangeiros da Faculdade de Educação e Serviço Social da Universidade de Sydney (USY), Austrália e uma pesquisadora júnior (Doutora em Educação); dois alunos de Mestrado e dois de Doutorado e oito alunos graduando da Pedagogia. Enquanto o grupo do CECS incluiu: 38 (trinta e oito) alunos e alunas entre 9 a 17 anos de idade, sendo 27 (vinte e sete) do $6^{\circ}$ ano e 11 (onze) do 90 ano. Desses 11(onze) alunos, 9 (nove) foram copartícipes da pesquisa.Este grupo incluiu ainda três professoras: a de português, a de matemática e a diretora adjunta como colaboradoras da pesquisa.

Os alunos e alunas do CECS são originários de comunidades que lidam diariamente com severas desigualdades sócio educacionais, vítimas de constantes violências e privações sociais e financeiras, constituindo assim, uma parte da sociedade que enfrenta extrema vulnerabilidade social.

O estudo foi conduzido entre agosto de 2010 a julho de 2013. Sendo que o

\footnotetext{
${ }^{5}$ Site do NetEDU disponível em www.netedu.pro.br.

${ }^{6}$ Embora seja norma do NetEDU omitir os nomes das escolas e participantes em suas pesquisas, este texto é uma exceção a esta norma, visto que se mantém o nome verdadeiro da escola assim como os dos participantes: professoras, alunos e alunas, visto que estes receberam recursos financeiros da FAPERJ e assim, podem comprovar junto a intuição os resultados dessa participação.
} 
período compreendido entre agosto de 2011a dezembro de 2012foi destinado ao trabalho de campo.Utilizou-se como instrumentos de pesquisa: observações participantes, entrevistas etnográficas, entrevistas em grupos focais, estudo de caso etnográfico, documentos e recursos digitais interativos. A parceria com alunos e alunas da escola pública foi o principal o foco dos procedimentos de coleta, análises, construção dos resultados e divulgação dos mesmos para a escola e o público em geral.

Gênero e Pobreza foram as categorias selecionadas pelo grupo da UERJ para orientar a busca de dados na escola.Entretanto o grupo do CECS solicitou a inclusão do tema "violências"como prioritário, devido às questões pelas quais a escola estava passando na época. Assim, estudou-se as categorias: Violências, Gênero e Pobreza. Pois, "as categorias ou temas que escolhemos para observar não são necessariamente escolhidos previamente [...] esta escolha se dá a partir do desenvolvimento do trabalho de campo" (MATTOS; CASTRO, 2011, p. 66).

A pesquisa foi desenvolvida em dois ambientes; o primeiro foi o laboratório do NetEDU, localizado na sala 12019, no $12^{\circ}$ andar da sede no Maracanã. A sala dispõe de rede de Internet, computadores de última geração e serve como sala de apoio às atividades e encontros do grupo de pesquisa. $O$ segundo foi as dependências do CECS, sendo que o laboratório de informática, a biblioteca e a sala do $6^{\circ}$ ano foram os espaços mais utilizadas para a pesquisa.

CECS é localizado no Bairro de Comendador Soares em Nova Iguaçu, região do Grande Rio, também conhecida Baixada Fluminense. Foi fundado em 1975, apresenta problemas sérios de infraestrutura que combinado com a pobreza e os assassinatos bárbaros que ocorrem no bairro, tornam a escola um lugar social e fisicamente vulnerável. Durante a pesquisa foi relatado na mídia uma chacina de jovens moradores do bairro. Por isso, no início do ano letivo de 2010 os professores se reuniram juntamente com a direção da escola para a elaboração do Projeto Político Pedagógico (PPP), que nos foi apresentado pela diretora adjunta. De acordo com esse documento e as explicações da diretora adjunta, o PPP teve como "tema gerador" a Campanha da Fraternidade veiculada pela Igreja Católica Apostólica Romana no Brasil, "Fraternidade e defesa da vida. Escolhe, pois, a vida [Dt 30,19]" (SELL, 2008). A proposta do PPP era a de que todos os funcionários da escola atuassem de forma participativa e colaborativa para o bom desenvolvimento das metas propostas a partir do objetivo geral que seria "despertar o senso crítico em relação à vida, o amor e a afetividade".

O diferencial do PPP desta unidade escolar, como nos explicou a diretora adjunta, estava na execução, em sala de aula e com a participação dos professores e alunos, dos subprojetos que estivessem em consonância com a sociedade atual, dentre eles o meio ambiente e o mercado de trabalho, levando em consideração as características dos alunos de cada segmento de ensino. Para a construção do PPP a equipe de funcionários da escola considerou os dados do ano anterior relativos à avaliação e aos índices de reprovação e evasão. A partir desses foram traçadas novas diretrizes em função dos problemas enfrentados anteriormente. Assim, os participantes propuseram que, em sala de aula, o "foco na leitura" e na "resolução de problemas e cálculos" seriam prioridades, e tais propostas seriam executadas em subprojetos elaborados pelos professores.

Com $2300 \mathrm{~m}^{2}$ de espaço, o edifício escolar é distribuído em nove salas de aula, uma biblioteca, uma secretaria, uma sala de professores, um escritório do Diretor, um refeitório, uma cozinha, quatro depósitos, seis banheiros, um auditório, 
sala de arquivos, sala de educação física, laboratório de informática e sala para a banda de música da escola.

A escola possui turmas do $6^{\circ}$ ao $9^{\circ}$ ano do Ensino Fundamental e o Ensino Médio de Formação Geral nos turnos da manhã, tarde e noite. À época da realização da pesquisa de campo, estavam matriculados no Ensino Fundamental, (695) seiscentos e noventa e cinco alunos e no Ensino Médio, (508) quinhentos e oito alunos. O corpo docente era integrado por 56 (cinquenta e seis) professores regentes distribuídos nas disciplinas: Português, Língua estrangeira, Ciências, Educação física, Matemática, Física, Sociologia, Filosofia, Geografia, Biologia, História, Química, Diversidade Contemporânea e Educação Artística. A escola possuía, ainda, 27 (vinte e sete) funcionários, sendo 7 (sete) de apoio técnico-pedagógico, um de coordenação pedagógica e dois de direção.

Os turnos eleitos para as observações foram: manha e tarde, com a frequência de uma vez por semana. Na UERJ a equipe se encontrou durante os três anos de estudo uma vez por semana, portanto dois dias da semana foram dedicados à pesquisa: segundas e quartas.

A parceria entre o grupo da UERJ e do CECS começou em 2004 no formato de um projeto de extensão universitária intitulado "Incluindo Diferenças: uma proposta de professores comprometidos com alunos em risco educacional", que foi apresentado à escola pela Diretora Adjunta a professora Riselda, que desde então é membro do NetEDU, tendo colaborado em diversos projetos de pesquisa anteriores a este.

Em entrevista à Silva (2014) a pesquisadora do grupo da UERJ - Paula Almeida de Castro relata:

[...] O início da parceria com a Escola Comendador Soares se deu através do contato com a Riselda e o

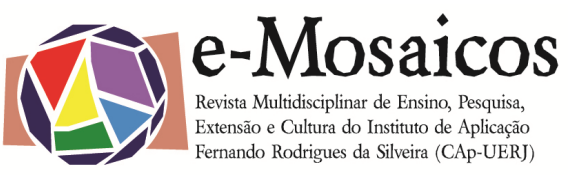

grupo de pesquisa. Na época Carmen tinha uma turma de PPP e eu era aluna de Mestrado. Junto com alguns alunos elaboramos oficinas para algumas escolas. Para a Comendador Soares elaboramos um material didático sobre bullying $\mathrm{e}$ fracasso escolar [...]essa parceria foi sendo reforçada ao longo dos anos, pois o grupo de pesquisa NetEDU transmitia credibilidade à escola demonstrando que as trocas eram mútuas (SILVA, 2014, p. 38).

Esta forma de pesquisar lida com a coparticipação dos alunos como agentes do conhecimento escolar e abre espaço para intercâmbios que contribuem para formar um forte senso de credibilidade e confiança, um ambiente saudável de respeito mútuo que fortalece os vínculos entre a escola e a equipe de pesquisa.

Os objetivos da pesquisa foram, entre outros, o de examinar como as diferenças de gênero, pobreza e violência são retratadas em sala de aula, ou seja, em que medida essas categorias influenciam as atividades e comportamentos na escola e se tornam indicadores do fracasso escolar entre os alunos e alunas. Assim como analisar de que modo as ordenações de gênero (CONNELL, 2002), a pobreza (ROSA, 2012) e as violências (ROSA, at. al., 2012; COELHO, 1988) servem como pontos de partida para construção de percepções dos alunos e alunas sobre: sua comunidade,seus colegas, seus professores e de como o grupo da UERJ os veem como pessoas.

Gênero e pobreza foram explorados pelas escutas das falas dos alunos e alunas do $6^{\circ}$ ano sobre suas histórias de vida na escola e fora dela. A intenção era compreender a relação entre esses temas e o fracasso escolar. Na categoria violências procurou-se explorar questões de como alunos e alunas percebem a escola. É este um espaço violento? A escola preci- 
sa abordar questões sobre as violências na comunidade? E ainda, se a violência é parte da sociedade, o que a escola pode fazer para remediá-la?

As análises que exploraram as histórias de vida de alunos e alunas, constituíram o foco principal para captar as impressões que eles próprios têm sobre suas vivências na escola. Elas foram usadas como estímulo para que eles projetassem o impacto que suas subjetividades têm sobre as suas trajetórias futuras, assim como para pensarem ações a realizar caso desejem ter uma escola sem violência, com menos pobreza e discriminação de gênero, e, portanto, mais justa e igualitária.

As classes do $6^{\circ}$ e 90 ano foram consideradas por serem representativas do que acontece na escola entre o primeiro segmento e o segundo segmento do Ensino Fundamental. Ambos os anos representam épocas de transição, quando os alunos se sentem incomodados com as mudanças que ocorrem (CASTRO, 2015). Estas mudanças incluem atitudes e valores dos alunos e professores sobre o significado da escola e dos estudos que nela se realiza. A seleção destas classes é justificada porque elas são geralmente atípicas em termos de representatividade do fracasso escolar. Nessas classes, a maioria dos alunos apresenta discrepâncias idadesérie de pelo menos dois anos de estudo. Além disso, em sua a maioria, a trajetória dos alunos é marcada pela repetência, pela pobreza- que os impelem a buscar uma forma de trabalho remunerado e,ainda, pelas mudanças da adolescência para a idade adulta, que alteram, fortalecem e intensificam as afirmações indentitárias de gênero quanto aos papéis da feminilidade e masculinidade na construção e manutenção das interações sociais na vida adulta.

O grupo da UERJ, sendo formado por acadêmicos, acreditava que por ser o grupo "mais poderoso" em termos das relações assimétricas de poder, comumente percebidas pela sociedade, ao envolver alunos e alunas cocompartilhar esse "poder", auxiliaria o grupo do CECS a apropriar-se das "memórias coletivas"(CASTRO, 2015 , p. 228) sobre as condições sociais em que viviam de modo a promover percepções positivas sobre as trajetórias já alcançadas por eles e assim impulsioná-los para uma percepção positiva de futuro. Essa forma de pensar do grupo da UERJ baseia-se na suposição de que sem equilíbrio de poder mutuamente compartilhado seria difícil conduzir a pesquisa em colaboração coparticipativamente de modo crítico. Para tal, foram selecionados em 2011, os 11(onze) alunos e alunas do $9 \circ$ ano do Fundamental, que se tornaram em 2012, os alunos do $1^{0}$ ano do Ensino Médio. A participação dos 11 (onze) alunos e alunas durou 8 meses, enquanto 9 (nove) permaneceram na equipe durante de agosto de 2011 até julho de 2013. Foram eles: Ludmila, Marlon, Deborah, Laiane, Greice Kelly, Jonathan, Amanda, Marcelo e Michael.

Inicialmente, as duas classes $\left(6^{\circ} \mathrm{e}\right.$ 90 ano) foram convidadas a participar do estudo fazendo declaração escrita ou desenho sobre suas preocupações sobre a escola e sua vida como aluno. Este material, juntamente com as imagens da sala de aula, foi analisado a fim de levantar questões para compor entrevistas, e também ajudou na preparação de videoclipes em que os professores atuavam na classe do $6^{\circ}$ ano. Nas imagens selecionadas destacavam-se as interações desses professores com seus alunos e dos alunos entre si. Foram realizadas entrevistas etnográficas com todos os participantes, inclusive comas professoras e a diretora adjunta, que assistiram suas próprias imagens em vídeo e as interpretaram junto com a equipe.

Depois de verem as imagens, as professoras expressaram suas opiniões e comentários sobre os alunos, responderam perguntas sobre o significado de algumas 
cenas que não estavam claras para a equipe e analisaram os objetivos de algumas tarefas propostas na sala de aula do $6^{\circ}$ ano. Após essas reuniões, os clipes de filmes e outros dados coletados foram transcritos e estudados. Desse processo surgiram subcategorias de análise associadas às categorias principais do estudo selecionados, elas constituem importantes resultados da pesquisa (MATTOS, 2013), mas não serão exploradas neste texto que trata do processo da pesquisa, mais do que dos seus produtos.

A participação dos alunos do 90 ano foi fundamental para o sucesso do trabalho, eles foram treinados para conduzir entrevistas com os alunos do $6^{\circ}$ ano, e este treinamento serviu como um despertar para as categorias de análise e também como um processo reflexivo de aprendizagens progressivas para esses alunos que, entre outras, desenvolveram habilidades para ouvir os outros. Eles treinaram primeiro com o grupo da UERJ, depois entre si. $O$ treinamento e o trabalho de campo duraram um ano. O objetivo era abreviaras questões a serem colocadas para os alunos do $6^{\circ}$ ano e promover a liberdade de expressão dos entrevistados. Os alunos do 90 ano entrevistaram os alunos do $6^{\circ}$ ano, sempre que possível individualmente, às vezes em pares, mas sempre com a assistência do grupo da UERJ.

As entrevistas promoveram vários momentos de surpresa, tanto da capacidade do entrevistador para conduzir as entrevistas quanto das sábias respostas obtidas dos entrevistados. Em suma, o conteúdo das respostas, muitas vezes excedeu, de longe, as expectativas da equipe de pesquisa. $O$ resultado confirmou que o envolvimento dos alunos entre eles permitiu maior liberdade e espontaneidade nas respostas do que se as entrevistas tivessem sido conduzidas por pesquisadores experientes do grupo da UERJ. As entrevistas foram observadas e filmadas ao longo do período de treinamento e coleta de dados, a fim de facilitar as análises e a aprendizagem da equipe sobre o seu próprio processo de evolução na pesquisa.

Vários desdobramentos surgiram a partir da experiência de pesquisa: criação de: uma peça de teatro; um blog; uma cartilha virtual e de clips de vídeos; criação de grupos interativos virtuais entre os dois grupos, com a participação em seminários de pesquisa, workshops e eventos na UERJ; participação do grupo do CECS como autores e coautores de artigos e pôsteres apresentados por eles próprios em congressos nacionais; e, coautoria em capítulos de livros, artigos científicos e trabalhos de conclusão de curso, entre os pesquisadores e alunos da UERJ.A título de ilustração serão elencados a seguir alguns desses desdobramentos e como eles cederam no contexto da pesquisa.

\subsection{A peça de teatro - criando e recriando sentidos, valores e cultura}

O aluno Marcelo do 90 ano, já no 10 Ensino Médio em 2012, coparticipante da pesquisa, escreveu uma peça sobre Cyberbullying [violência virtual]. O contexto da escrita da peça se deu a partir do consenso entre os membros da equipe de que os alunos entrevistados ( $6^{\circ}$ ano) sabem as causas e consequências da violência e não percebem o dano que a prática do bullying [violências na escola] e do Cyberbullying pode causar entre eles dentro e fora da escola. Assim, o grupo da UERJ decidiu realizar um workshop sobre o tema bullying [violências na escola], dirigido ao grupo do CECS, consequentemente, os estudantes da escola decidiram que produziriam uma peça dramática sobre Cyberbullying (Figura 2). A peça foi escrita, roteirizada, produzida e dirigida por Marcelo e interpretada por alunos e alunas do $1^{0}$ ano do Ensino Médio. O roteiro foi revisado por alunos do grupo da UERJ. A peça foi apresentada na própria escola, primeiro para os participantes da 
e-Mosaicos - Revista Multidisciplinar de Ensino, Pesquisa, Extensão e Cultura do Instituto de Aplicação Fernando Rodrigues da Silveira (CAp-UERJ)

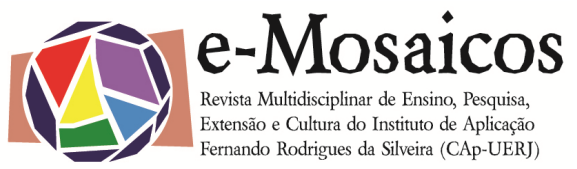

pesquisa e depois para toda a Escola e, posteriormente, fez parte das atividades culturais do evento anual da universidade intitulado "UERJ Sem Muros", realizado de 23 a 27 de setembro de 2013.

Figura 2: Peça Cyberbullying - CECS.

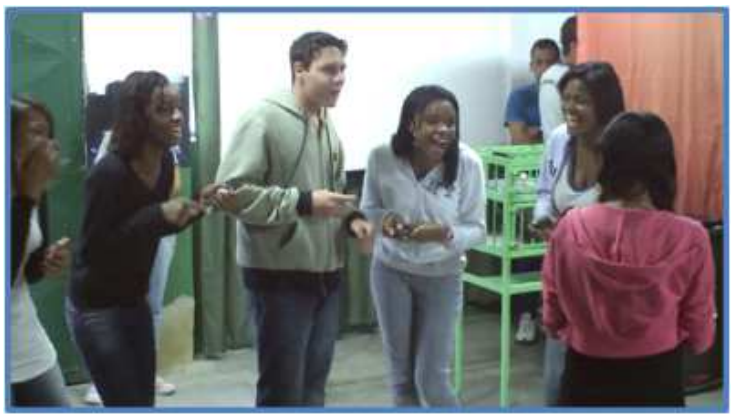

\subsection{As oficinas - Bullying e Cyber- bullying}

Os estudos sobre as violências resultaram na realização de oficinas sobre Bullying e Cyberbullying. A primeira foi intitulada: Oficina de Bullying: Combate a violência na escola (Figura 3). Esta oficina foi realizada na UERJ com a participação dos dois grupos e ministrada por uma aluna de graduação. Nela, os participantes fizeram relatos de situações cotidianas e opiniões sobre o bullying, destacando a importância do tema. A partir das falas dos participantes, os temas foram ampliados, assim com a compreensão sobre como o uso de ferramentas computacionais, da internet, e de outros aparatos digitais podem contribuir para a violência. Neste contexto concluiu-se que o a violência pelo Bullying está conectada ao Cyberbullying, sendo uma a continuação da outra. Elas começam na escola com o tradicional bullying escolar e com as novas tecnologias interativas os agressores, não satisfeitos com a prática presencial, incitam uma nova versão desse processo.
Figura 3: Oficina Bullying - UERJ.

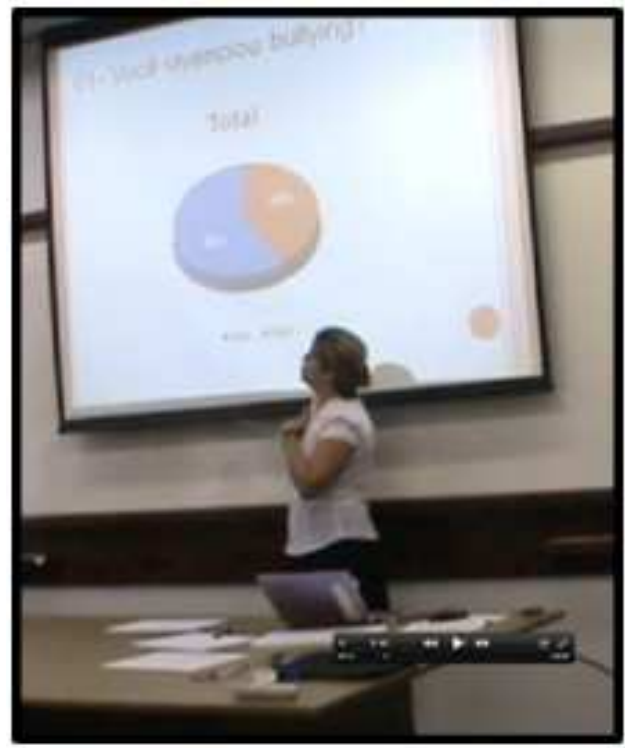

\subsection{O Blog - A Diferença Soma7}

O Blog, (Figura 4), foi criado pelo grupo do CECS em colaboração com o grupo da UERJ. Nele os eventos e os materiais produzidos durante as diferentes fases da pesquisa foi disponibilizado para acesso de toda a comunidade escolar. O objetivo foi promover discussões entre a equipe de pesquisa e a comunidade escolar sobre os temas: violências, bullying e gênero, associando estes temas às adversidades presentes na escola que implicam em atos de injustiça social, discriminação e violência. Além disso, esse é um espaço onde os alunos expressam suas opiniões e divulgam as atividades desenvolvidas por eles na pesquisa. Nele podem ser encontrados trechos das transcrições das entrevistas realizadas durante a pesquisa, onde se destaca o tema da violência, tanto na família, como na escola, bem como narrativas de como estas violências são recorrentes na vida dos entrevistados. Seu in-

$\begin{array}{lcccr}7 & \text { Acesso } & \text { ao } & \text { Blog } & \text { em } \\ \text { <http://menteabertaumnovoolhar.blogspot.com.br> }\end{array}$ 
tuito foi alerta a comunidade escolar sobre a importância do respeito às diversidades e às diferenças na prevenção da intolerância e da discriminação, assim como para evitar violências na escola e fora dela.

Figura 4: Blog.

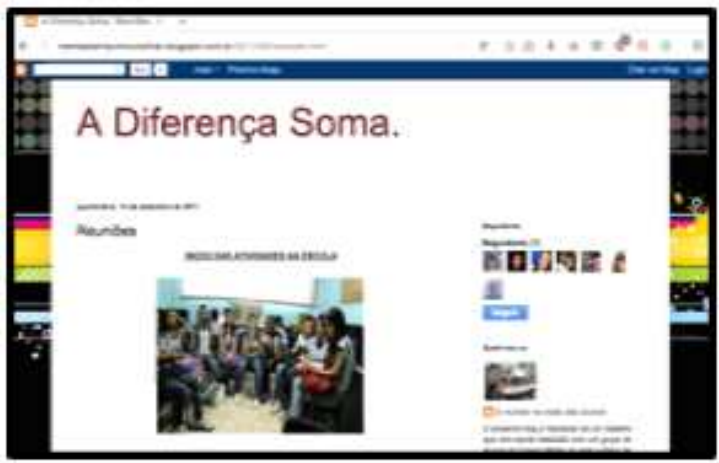

\subsection{A Cartilha Digital "Mais amor por favor"}

A iniciativa para a elaboração da cartilha digital começou como uma atividade da disciplina de Língua Portuguesa, as classes do $6^{\circ}$ e do 90 criaram textos e desenho sobre a violência escolar (Figura $5)$, eles serviram de base para a elaboração de uma cartilha digital (Figura 6). A proposta do grupo do CECS foi de relatar a percepção dos alunos sobre a violência na escola. Em colaboração com a professora, a equipe da UERJ publicou a cartilha através de site ${ }^{8}$ de acesso aberto.

O objetivo foi de promover junto à comunidade escolar ações de boa convivência na escola e alertar a comunidade nos arredores da escola sobre as violências, ressaltando a necessidade do esforço coletivo para envolver a escola e a comunidade no combate da violência. A linguagem, mensagens de simples entendimento, assim como os desenhos facilitaram a

8 Acesso à Cartilha Digital pelo link <http://www.youblisher.com/p/659705-Mais-amorPor-Favor/> compreensão do texto. A cartilha foi também distribuída na comunidade escolar com objetivo de minimizar a violência fortalecendo a importância da educação pela paz.

Figura 5: Desenho que inspiraram a CartiIha.

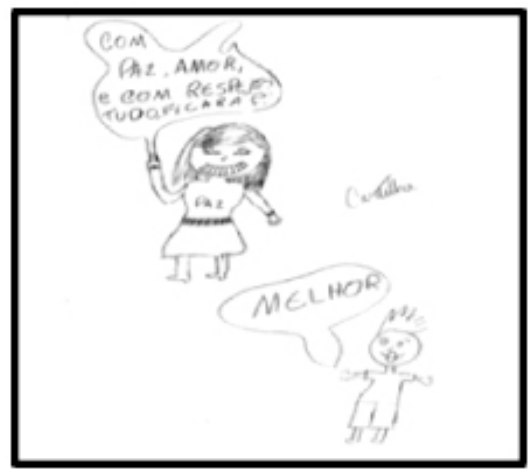

Figura 6: Cartilha digital.

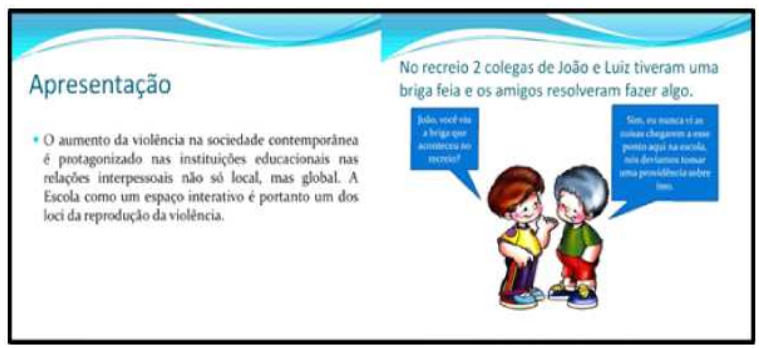

\subsection{Visitas à UERJ - A universidade como um espaço de todos}

Um terceiro desdobramento da pesquisa foi a organização da atividade de extensão "Café com pesquisa"9 que, no período da pesquisa, viabilizou conferências,sobre os temas estudados. Essas conferências foram ministradas por pesquisadores nacionais e estrangeiros como: Ra-

9 As atividades do "Café com Pesquisa" podem ser encontradas no site do NetEDU no link http://www.netedu.pro.br/netedu/cafe-compesquisa/ 
e-Mosaicos - Revista Multidisciplinar de Ensino, Pesquisa, Extensão e Cultura do Instituto de Aplicação Fernando Rodrigues da Silveira (CAp-UERJ)

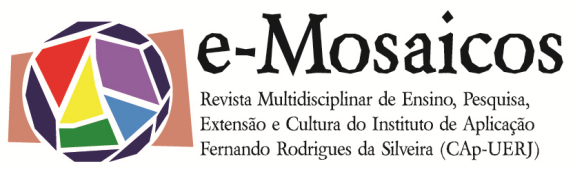

ewyn Connell (AU), Elizabeth Cassity (AU) Nigel Bagnall (AU), Valentina Grion (IT) e Cristina Devecchio (UK), Sandra Maciel (UFF), Walcea Barreto Alves (UFF), entre eles os que participaram como pesquisadores no campo. Houve a presença frequente dos grupos com a participação de todos nos debates teóricos sobre os temas (Figura 7).

Figura 6: Participação no Café com Pesquisa.

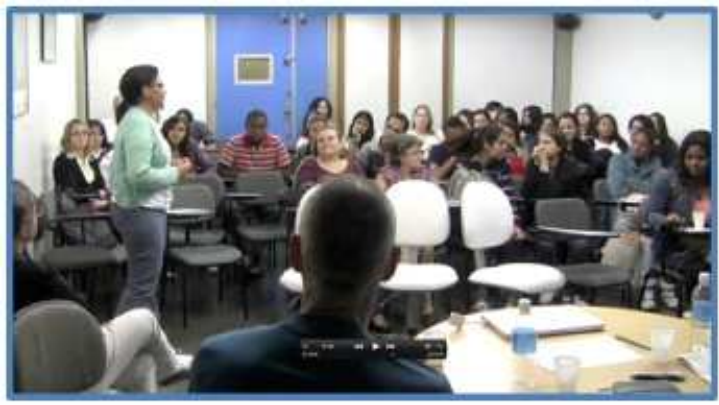

\subsection{Participação na construção e di- vulgação dos resultados da pesquisa}

A construção de textos e a apresentação dos resultados da pesquisa no Congresso Anual da Sociedade Brasileira de Ciência (SBPC) (Figura 8) e no evento "UERJ sem Muros" em 2012 foram alguns dos momentos que demonstraram a coparticipação dos alunos e alunas na equipe. Quase sempre excluídos dessa fase, por se sentirem intimidados na presença "avaliadora" de acadêmicos das universidades, os alunos, participaram ativamente desses eventos. As principais formas de participação foram: edição de clipes de imagens de vídeos; seleção das falas das entrevistas, escritas de vinhetas etnográficas; escrita dos textos e resumos; elaboração das oficinas e reedição da peça para um público maior na UERJ; assim como, a organização das viagens para os locais dos eventos. O ponto principal da construção dos resultados foi demonstrar que o processo reflexivo dos alunos envolvidos nas diferentes etapas do trabalho evidenciou formas de superação das desigualdades educacionais que os fragilizam como pessoas.

Figura 7: Participação na SBPC 2012.

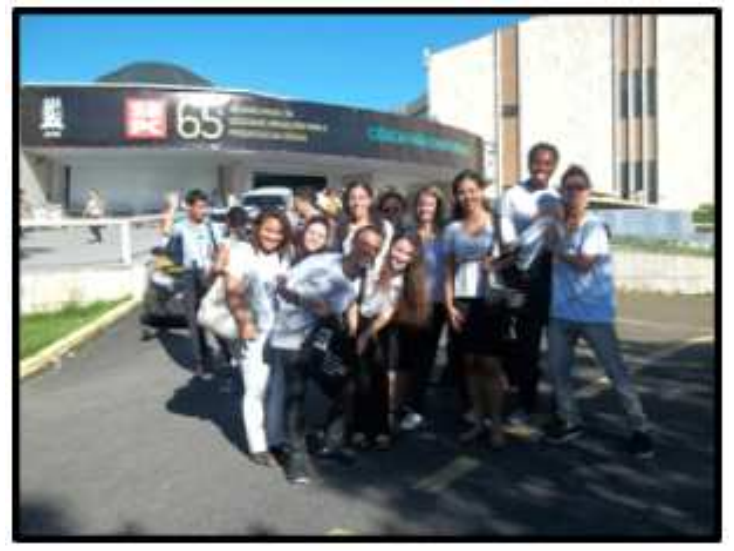

\section{Discussões e Conclusões}

Nesta seção serão discutidas as falas dos participantes como parte dos resultados e conclusões da pesquisa. Serão acentuadas as narrativas, subjetividades e reflexividades dos coparticipantes da pesquisa de modo a ilustrar as suas formas de entendimento e mudanças de atitudes, saberes, valores e maneiras de ver o mundo que permearam suas presenças na equipe (OLIVEIRA at. al. (2013a, 2013b). Em etnografia as conclusões ficam por conta do leitor, assim espera-se que as falas e as interpretações descritas possam suscitar os possíveis debates sobre o tema proposto (MATTOS, 1992).

Marcelo, cursa Psicologia na UERJ (ingressou em 2015.2) é um jovem de 21 anos de origem africana por parte do pai, nascido em Angola, perdeu sua mãe aos 8 anos de idade e foi sistematicamente rejeitado pelo pai.Iniciou na pesquisa em 2011, na época vivia com o pai, mas mudou-se posterior mente para a casa de uma tia no bairro de Comendador Soares, perto da escola. Ele pertencia a turma do $9^{\circ}$ ano e liderou o grupo do CECS impulsi- 
onando os seus colegas a coparticiparem como pesquisadores no estudo. Hoje, ele mora sozinho em um pequeno apartamento, pago com recursos de bolsa de estudos da UERJ e trabalhos temporários, e é bolsista na equipe atual. Sua coparticipação na pesquisa foi surpreendentemente positiva, pois é extremamente inteligente e articulado. Ao final da pesquisa Marcelo foi entrevistado pela coordenadora do estudo sobre o que aprendeu com a sua participação, ele disse:

Esses anos na pesquisa foram muito bons, mas foi um choque no início, porque estávamos tentando falar sobre questões de gênero e eu pensando que os alunos do $6^{\circ}$ ano não sabiam nada sobre isso. Mas, eles sabiam tudo e foi um choque para mim saber isso. A pesquisa abriu nossas mentes, porque havia uma barreira e não podíamos ver essas questões na escola, mas com as reuniões na UERJ e com as entrevistas, percebemos que era muito importante para nós, ficamos espantados com o que poderíamos ter, o que tínhamos nas mãos e ainda temos (MARCELO, em entrevista a MATTOS em 06.10.2013, na UERJ).

A reflexividade de Marcelo evidencia momentos de transição dele de aluno para aluno/ pesquisador enfrentamento os temas da pesquisa que os próprios alunos elegeram para perguntar aos colegas. Ao entrevistar os alunos do $6^{\circ}$ ano, ele conta que se surpreendeu com os conhecimentos que eles tinham sobre questões consideradas tabu na escola, assim como expressou a percepção negativa que possuía sobre o nível de entendimento desses alunos sobre os temas investigados. Sobre esses temas ele conta;

[...] Falando de gênero eu não posso esquecer da Julia, menina de
12 anos de idade do $6 \circ$ ano que nos chocou com a facilidade e a maneira pela qual ela disse, e pelo que disse. Julia tocou em um assunto que para nós era um tabu! Ela falou da maneira mais natural que seu tio era "travesti" e sua tia era "sapatão". Ela falou sobre a violência doméstica que sofria dizendo que ela pediu ao pai, como presente de aniversário, uma arma para matar seu tio que a estava assediando sexualmente e fazendo a sua tia de vítima, batendo e abusando dela.

[...]. Falar sobre a pobreza aqui na escola é muito fácil, quando eu comecei a pesquisar eu não pensei sobre o meu bairro, mas então eu estava vendo o meu bairro é um dos mais pobres por aqui. Um grande número de alunos vem para a escola e fala - tia (professora) me deixe comer!Em casa não tem comida!! [....] Eu acho que para os professores é muito pesado lidar com isso!Educar e alimentar - em vez de [eles] terem alimentos em casa. Eu não posso generalizar, mas no meu bairro esta é a realidade!(MARCELO, em entrevista a MATTOS em 06.10.2013, na UERJ).

Ele é crítico à realidade dos alunos e da escola e expressa com clareza os objetivos da pesquisa etnográfica quando revela:

[...] Uma das coisas mais importantes que aprendi na pesquisa foi ouvir, ouvir o outro, ouvir os alunos. Esse foi uma das falas de uma colega da equipe, ela disse - não nos ouvimos uns aos outros, e agora aprendemos a ouvir, perguntamos e ouvimos o que elas queriam dizer, não o que nós queríamos que elas dissessem. Agora, aprendemos a ouvir, a refletir sobre o significado do que o outro está falando sem induzir as pessoas a dizer o que queremos. Ouvir é refletir sobre o 
pensamento. É ser capaz de dizer, entender, ser capaz de mudar. Mudar nossa realidade (MARCELO, em entrevista a MATTOS em 06.10.2013, na UERJ).

Jovem pobre que ascendeu ao curso universitário em um período crucial de seu desenvolvimento acadêmico e profissional, Marcelo é um exemplo bemsucedido de como a inclusão de alunos na pesquisa é relevante, porque não dizer um divisor de águas entre o fracasso e o sucesso escolar. Contingenciado pela pobreza, moradia, família e cultura, ele viu na coparticipação um caminho tornando viável a vida em outras condições. Ele abraçou com força a oportunidade de compartilhar sua vida com outras pessoas e lugares e assim, modificou sua trajetória escolar.

Como Marcelo, outros alunos e alunas do Grupo do CECS também mudaram a partir da coparticipação. Eles falaram sobre as limitações da escola e da realidade em que viviam, assim como do potencial que possuíam, através dos estudos, de superarem o fracasso educacional, um dos contingentes dessa realidade.

Uma das evidencias desta conscientização crítica foi que 7 (sete) desses alunos entraram para a Universidade,e apenas uma das alunas não conseguiu terminar o ensino médio devido a uma gravidez inesperada. Até 2013, ano de conclusão do ensino médio para esses alunos, o CECS não havia conduzido nenhum aluno ao ensino superior. Esta marca histórica na escola mostrou que a coparticipação desses alunos na pesquisa oportunizou a superação de limites inéditos na vida deles. O contato com a UERJ, não só físico, mas pedagógi$\mathrm{Co}$, com o ambiente universitário, significou muito para eles. Eles aprenderam o que é ser um estudante universitário e o que precisariam enfrentar para superar as desigualdades entre eles e os alunos universitários. Eles transformaram o determi- nismo do fracasso acadêmico em desafio, enfrentando com mais segurança, junto a equipe, a possibilidade de sucesso. Esse fato é ilustrado pelas frases escritas pelos alunos e alunas do 90 ano:

Foi gratificante chegar até aquele lugar, ver a resposta do estudo, alunos com verdadeiro intuito de crescer na vida. Essa pesquisa vem sendo uma grande oportunidade para o desenvolvimento social e tem ajudado a melhorar a forma de comunicação entre os alunos. 0 dia na UERJ foi muito gratificante, nos fez aumentar 0 interesse pelo estudo, para que seja possível futuramente estudarmos lá. Essa experiência foi muito interessante, tudo o que vimos e ouvimos durante a palestra sobre refugiados na África (referindo-se à conferência ministrada pela pesquisadora Elizabeth Cassity), uma oportunidade de conhecermos o que acontece lá fora. Estar no meio de sujeitos que formam a universidade, professores, alunos e todos que estavam ali presentes, trocando ideias, conhecimentos, entre outras propostas. Foi realmente um dia especial! (Ludmila, texto publicado no Blog "A Diferença Soma", em 14/09/2011).

A ida à UERJ foi sensacional. Alunos de uma escola estadual indo para uma universidade estadual realizar um projeto e conhecer mais sobre os cursos, como são as pessoas na faculdade, o que tem na faculdade, como é estar dentro de uma faculdade, particularmente foi espetacular. Quando todos chegaram à faculdade reagiram gritando, pulando, estavam com uma felicidade enorme. Conhecemos os cursos existentes no local, assistimos a palestra com a professora Elizabeth que relatou a pesquisa realizada com refugiados, ouvimos música na Van e a tarde tivemos um lanche. Portanto a ida na UERJ foi gratifi- 
cante para o grupo, pois com esse momento tivemos a oportunidade de nos conhecer melhor, construir uma grande amizade. Até as qualidades e defeitos de cada um chegamos a comentar. Enfim, estar podendo sair do colégio e ir para um lugar diferente, conhecer coisas novas, é bom para qualquer um. É mais amadurecimento, conhecimento, capacitação, alegria e é claro divertimento (Jonathan, texto publicado no Blog "A Diferença Soma", em 14/09/2011).

A ida à UERJ foi uma experiência muito grande, a partir desse dia eu pude realmente perceber 0 que quero fazer no meu futuro. Logo que eu entrei no transporte para ir a UERJ já deu um frio na barriga, a minha ficha ainda não tinha caído. Mas chegando lá fui me acostumando com o ambiente, com as pessoas, eu estava me sentindo um universitário. A hora muito marcante foi a apresentação da pesquisa da Elizabeth, pois pude ver como é lá fora, como as pessoas são tratadas. Foi muito importante ter participado desse evento. Outra parte que marcou muito também foi 0 tour pela universidade, aonde vimos as salas, a mandíbula da baleia.... Concluindo, foi muito bom! (Michel, texto publicado no Blog "A Diferença Soma", em 14/09/2011).

Estas declarações complementam as falas de Marcelo no final do processo de pesquisa que se faz presente nos ensinamentos de Paulo Freire sobre a relação educador e educando que, segundo ele,se constrói de maneira horizontal, sem imposições e hierarquias. A partir do momento que $o$ aluno se liberta da autoridade representada na assimetria de poder entre ele o professor e/ou o pesquisador, se inicia nele um pensar crítico e libertador e com isso a democratização da cultura e do saber associado a ele, em um processo de conscientização e criticidade voltado para o político que é parte dele. Para isso diz o mestre" o educando precisa assumir-se como tal, mas assumir-se [...] significa reconhecer-se como sujeito [...] em [sua] relação com o outro sujeito igualmente capaz de conhece" (FREIRE, 2003, p. 47). Do mesmo modo, ensinar e aprender implicam em se reconhecer.

Em conclusão, este texto discute como pensar a educação para os sujeitos do conhecimento (FAGUNDES, 2011) considerando suas opiniões, desejos e interesses. A equipe de pesquisa criou um diálogo aberto entre os seus membros e através deste construiu e reconstruiu significados e vicissitudes que impulsionaram novas formas de interpretar, ver e ouvir a realidade a partir do outro. Através da coparticipação, as realidades educacionais de alunos alunas e dos pesquisadores dos dois grupos da equipe de pesquisa se transformaram.

\section{REFERÊNCIAS BIBLIOGRÁFICAS:}

ALVES, W. B. A Escola no Espelho: as representações do aluno. Tese (Doutorado) Programa de Pós-Graduação em Educação, Universidade Federal Fluminense, Niterói, 2012. 158 p.

ALVES, W. B. A Reflexividade na Pesquisa Etnográfica. Dissertação (Mestrado). Programa de Pós-Graduação em Educação, Universidade do Estado do Rio de Janeiro, Rio de Janeiro, 2003. 248 p.

BECK, U. A Reinvenção da Política: rumo a uma teoria da modernização reflexiva. In: BECK; GIDDENS; LASH. Modernização Reflexiva: política, tradição e estética na ordem social moderna. Tradução de Magda Lopes. São Paulo: Editora da universidade Estadual Paulista, 1997. pp. 11-72 
BOURDIEU, P. O poder simbólico. Tradução Fernando Tomaz. $8^{a}$ ed. Rio de Janeiro: Bertrand Brasil, 2005.

CASTRO, P. A. de Tornar-se Aluno: identidade perspectivas etnográficas. Campina Grande: EDUEPB, [online], 2015, 272 p.

CASTRO, P. A. de. Controlar para quê? Uma análise etnográfica do controle na interação entre professor e aluno na sala de aula. Dissertação (Mestrado) Programa de Pós-graduação em Educação, Universidade do Estado do Rio de Janeiro, 2006.

COELHO, M. I. M. Violência na escola, educação e formação humana: uma perspectiva etnográfica. Relatório de Conclusão de Estágio de Pós-Doutorado, Programa de Pós-graduação em Educação, Universidade do Estado do Rio de Janeiro, Rio de Janeiro, 2008.

CONNELL, Raewyn W. Gender. Cambridge: Polity Press. ( $1^{\mathrm{a}}$ ed.), 2002.

COOK-SATHER, A. Authorizing student perspectives: Toward trust, dialogue, and change in education. Educational $R e-$ searcher, 31, 4, 3-14, 2002.

COOK-SATHER, A. Student Voice: Past Efforts, Current Trends, and Future Possibilities University of Cambridge Faculty of Education, Slides Presentation, 1 julho de 2011. Disponível em <https://cambridg estudentvoiceseminars.wordpress.com/> Acesso em 3 de fevereiro de 2017.

ERICKSON, F. Research Currents: Learning and Collaboration. In Teaching. Reprint from Language Arts, 1989. pp. 430-440.

ERICKSON, F. Studying side by side: Collaborative action ethnography in educational research. In Spindler; Hammond (eds.) New horizons for ethnography in education, Mahwah, NJ: Lawrence Erlbaum and Associates, 2006. 235-257p.
FAGUNDES, T. B. A pesquisa docente: sobre o conceito de professor pesquisador na formação inicial de agentes de letramento. Dissertação (Mestrado). Programa de Pós-graduação em Educação, Universidade do Estado do Rio de Janeiro, Rio de Janeiro, 2011.157 p.

FINE, M. Entrevista com Michele Fine. Realizada por Carmen Lúcia Guimarães de Mattos na City University of New York (CUNY), USA, em 22/02/2013. Formato MOV, duração de 100.20 p. (não publica$\mathrm{da})$

FREIRE P. Cartas a Cristina: reflexões sobre minha vida e minha práxis. $2^{a}$ ed. São Paulo: UNESP, 2003.

GIDDENS, A. As consequências da modernidade. São Paulo: Unesp, 1990.

GOFFMAN, E. A representação do eu na vida cotidiana. Petrópolis: Editora Vozes,1985.

GRION, V.; COOK-SATHER, A. (Org.) Student Voice. Prospettive internazionali $e$ pratiche emergenti in Italia. Milano: Guerini, 2013.

LASH, S. A Reflexividade e seus duplos: estrutura, ética, comunidade.In: BECK, Ulrich, GIDDENS, Anthony, LASH, Scott. Modernização Reflexiva: política, tradição e estética na ordem social moderna. Tradução de Magda Lopes. São Paulo: Editora da universidade Estadual Paulista, 1997. pp. 11-72.

MATTOS, C. L. G. de Picturing school failure: a study of diversity in explanations of "educational difficulties" among rural and urban youth in Brazil. Thesis (Ph.D. in Education) - Graduate School of Education, The University of Pennsylvania. Philadelphia. USA, 1992. 268p. 
MATTOS, C. L. G. de; CASTRO, P. A. de. (Org.) Etnografia e educação: conceitos e usos [online]. Campina Grande: EDUEPB, 2011. 298 p.

MATTOS, C. L. G. de; FONTOURA, H. A. da. (Org.) Etnografia e Educação: relatos de Pesquisa. Rio de Janeiro: Eduerj, 2009.

MATTOS, C. L. G. de. at al. (Org.) Pesquisas em Educação: a produção do Núcleo em Etnografia e Educação (NetEDU). [Livro Eletrônico] Campina Grande: Realize, 2015, 358p.

MATTOS, C. L. G. de. Etnografia Crítica de Sala de Aula: o Professor Pesquisador e o Pesquisador Professor em Colaboração. Revista Brasileira de Estudos Pedagógicos, Brasília, V. 79, n. 182/183, p 98-116, jan/ago,1995.

MATTOS, C. L. G. de. Gênero e Pobreza: Práticas, Políticas e Teorias e Tecnologias Educacionais - Imagens de escolas. Relatório Final de Pesquisa. Rio de Janeiro: FAPERJ, 2013, 58 p.

MATTOS, C. L. G. de. Metacognição em Sala de Aula - Relatório final de Pesquisa. Rio de Janeiro; DEGASE/UERJ, 2000.

MATTOS, C. L. G. DE.; ALVES, W. B. Outros saberes sobre s escola: a voz do aluno na pesquisa em educação. XVII ENDIPE - Encontro Nacional de Didática e Prática de Ensino. Universidade Estadual do Ceará, Fortaleza: EdUECE, [Eletrônico Livro 1], 2015, p.12.

MOURÃO, L. M. A reflexividade dos jovens do Ensino Médio sobre o contraste tecnológico entre a escola pública e a sociedade. Dissertação (Mestrado) Programa de Pós-graduação em Educação, Universidade do Estado do Rio de Janeiro, Rio de Janeiro, 2006. 102p.
MOURÃO, L. M. Estudo etnográfico das percepções de alunos da Educação Básica sobre a TV Tese (Doutorado) Programa de Pós-graduação em Educação, Universidade do Estado do Rio de Janeiro, 2011. 146p.

OLIVEIRA, J. L. at al. Pesquisa etnográfica em uma escola pública do Rio de Janeiro: a contribuição para a formação do aluno pesquisador. In: 65a Reunião Anual da SBPC, Recife: SBPC, 2013a.

OLIVEIRA, R. M. F. at al. O uso de tecnologias digitais no Colégio Comendador Soares para o enfrentamento da violência escolar - a criação de um @book para a comunidade. In: $65^{a}$ Reunião Anual da SBPC, Recife: SBPC, 2013b.

ROSA, A. V. A. at al. de. Violência Escolar na perspectiva de alunos e alunas da rede pública de ensino. In 62a Reunião Anual da SBPC. São Luís: SBPC, 2012.

ROSA, A. V. A. Pobreza e Educação: um estudo teórico epistemológico sobre a produção do conhecimento no período de 2000 a 2010. Dissertação (Mestrado) Programa de Pós-graduação em Educação, Universidade do Estado do Rio de Janeiro, 2012. 169p.

SELL, D. Fraternidade e defesa da vida. Escolhe, pois, a vida! (Dt. 30,19) Encontros Teológicos, № 49, Ano 23, número 1, 2008.

SILVA, F. M. B. da. Diálogo entre escola e universidade públicas: um estudo sobre a pesquisa na Escola Estadual Comendador Soares na perspectiva do sujeito aluno da escola. Monografia (Pedagogia) Faculdade de Educação, Universidade do Estado do Rio de Janeiro, Rio de Janeiro, 2014. 64p. 